\title{
Language Foregrounding and Structure of Literary Functions in Hossein Monzavi's Sonnet Using Leach's Linguistic Model
}

\section{Primer plano del lenguaje y estructura de las funciones literarias en el soneto de Hossein Monzavi utilizando el modelo lingüístico de Leach}

\section{Narges Abdollahi}

Department of Persian Language and Literature, Arak Branch, Islamic Azad University, Arak, Iran.

ORCID: https://orcid.org/0000-0002-2033-0993

\section{Ali Sarvar Yaghoobi*}

Department of Persian Language and Literature, Arak Branch, Islamic Azad University, Arak, Iran.

ORCID: https://orcid.org/0000-0002-6456-5575

\section{Shahrokh Hekmat}

Department of Persian Language and Literature, Arak Branch, Islamic Azad University, Arak, Iran.

ORCID: https://orcid.org/0000-0002-9143-4036 


\section{Summary}

Deviation and structural critique, as features distinguishing literary language from normative language, are the most fundamental concepts in structuralism theory. In this century, structuralism is a scientific and common approach to evaluate the artistic characteristics of literary works. Geoffrey Leach, an English structuralist, classified literary features (deviations) in eight levels: (1) lexical, (2) grammatical, (3) phonological, (4) graph logical, (5) dialectical, (6) stylistic, (7) semantic, and (8) historical period. He distinguished these linguistic deviations from other deviations by using three features of position, direction, and conclusiveness. His model is generalizable to all languages, especially Persian. Forasmuch, as Monzavi's sonnet, has a specific position in the contemporary Persian poetry. This study aimed to find language deviations in Monzavi's sonnets using descriptive-analytical method within the framework of the structuralism and based on Leach's deviation Model. Accordingly, the poet's deviations and artistic creations are often sought for simplicity in the language of poetry and its approach to common language (simple and impossible). In general, the most frequent type of deviation in Monzavi's sonnet in both qualitative and quantitative terms is semantic deviation.

Keywords: Language foregrounding, Literary function, Structure, Geoffrey Leach, Hossein Monzavi's sonnet.

\section{Resumen}

La desviación y la crítica estructural, como características que distinguen el lenguaje literario del lenguaje normativo, son los conceptos más fundamentales de la teoría del estructuralismo. En este siglo, el estructuralismo es un enfoque científico y común para evaluar las características artísticas de las obras literarias. Geoffrey Leach, un estructuralista inglés, clasificó las características literarias (desviaciones) en ocho niveles: (1) léxico, (2) gramatical, (3) fonológico, (4) lógico gráfico, (5) dialéctico, (6) estilístico, (7) ) semántico, y (8) período histórico. Distinguió estas desviaciones lingüísticas de otras desviaciones utilizando tres características de posición, dirección y contundencia. Su modelo es generalizable a todos los idiomas, especialmente al persa. Por tanto, como soneto de Monzavi, tiene un lugar específico en la poesía persa contemporánea. Este estudio tuvo como objetivo encontrar las desviaciones del lenguaje en los sonetos de Monzavi utilizando el método descriptivo-analítico en el marco del estructuralismo y basado en el Modelo de desviación de Leach. En consecuencia, las desviaciones y creaciones artísticas del poeta se buscan a menudo por la simplicidad en el lenguaje de la poesía y su acercamiento al lenguaje común (simple e imposible). En general, el tipo de desviación más frecuente en el soneto de Monzavi tanto en términos cualitativos como cuantitativos es la desviación semántica.

Palabras clave: Primer plano del lenguaje, Función literaria, Estructura, Geoffrey Leach, Soneto de Hossein Monzavi.

\section{Introduction}

The concept of artistic "highlighting" has underpinned research by formalists and structuralists' literary critics over the last century. "Emphasis" is the use of language elements in such a way that makes its expression attractive and unconventional. Highlighting deviation from language is standard when a linguistic element is used in the usual way and attracts the attention of the audience. Mukarfsky considers highlighting to be a conscious process and believes that the more consciously the process is used, the less automated it is. The factors of two principles "conductivity" and "aesthetics" are of great importance (Safavid, 2011). When discussing highlighting, Shafiei Kadkani points out that the types of highlighting can be explained in both 
musical and linguistic groups (Shafiei Kadkani, 2013) and considers the musical group as a set of factors combining elements such as weight, rhyme, order, and harmony. According to him, language group is a set of factors that can be highlighted by differentiating the vocabulary in the sentence system. In this case, he enumerates factors such as metaphor, permission, brevity, and so on. Shafiei Kadkani hold a view partly similar to Leach's. Leach has proposed what Shafiei Kadkani puts forward in the context of a musical group in a general category, called balance or augmentation rule, and considers the linguistic group to be explainable using a variety of abnormalities or straw rules (Sojudi, 1999). In his theory, abnormality goes so far that communication is not disrupted. In other words, he believes that any deviation from the rules governing the normative language cannot be called norm-breaking in the direction of creativity; hence, he specifies some prerequisites in this regard. He considers three possibilities for distinguishing between artistic embossing and other embellishments:

1.There is an emphasis when abnormality expresses a concept or, in other words, it plays a role.

2. There is an emphasis when aberration expresses the intention of the speaker or, in other words, it is directional.

3. There is an emphasis when aberration from audience's perspective expresses a concept or, in other words, it is purposeful (Sojudi, 1999).

Tricks and techniques highlighting the language of poetry make the audience turn from meaning to language and linguistic elements. In this way, meaning is used by language, and the art, including literature, is to make these concepts unfamiliar (Alawi Moghaddam, 2003: 10). Leach considers the emphasis of poetry as a deviation from the rules of normal language and divides it into eight categories: (1) lexical, (2) syntactic, (3) phonetic, (4) written, (5) "Dialect (dialect), (6) Stylistic (deviation from the functional type of language), (7) Semantic, and (8) Temporal (deviation from a specific historical period, archaism)" (Khalili Jahanatigh, 2001).

Every artistic phenomenon has constituent components, which distinguish it from other ordinary and everyday phenomena. The elements that make the phenomenon stand out and become artistic are studied under the heading of literary function or de-familiarization. Literary works are considered as artistic phenomena as they have mastered the standard and scientific language, and literary features (literariness) are distinguishing them from other writings. The study of literary features and their analysis is a scientific method directing researchers regarding the structure of a literary work. In other words, recognizing and studying literary elements in texts of order and prose refers to the methodology of literature.

\section{Literary Elements}

A literary work can be classified into two levels: regularization and straw. Regularization refers to phonetic relations and coherence in the horizontal and vertical axis of speech, which includes the sciences of pronouns, rhymes, and rhetoric. The straw rule is the deviation of words from the standard language, in which the speaker or writer goes beyond the conventional rules of language and leaves his imagination in a wider space. The straw rule is also called literary function or defamiliarization and encompasses sciences such as grammar, historical grammar, lexicography, expression, meanings, spiritual novelty, and so on.

Over the past century, formalist and structuralist literary critics have sought to provide coherent methods to criticize literary texts so that the space of criticism is free from the dust of blind emotion and bias. One of the most coherent theories in this field is the octagonal classification of linguistic metaphors (literary functions) proposed by Jeffrey Leach, an English structuralist who matches the patterns of different languages.

\section{Statement of problem and research questions}

Ghazal has been a popular poetic dated back to more than a thousand years, which has continued its life in Persian literature and has taken on a new form with a new approach and theme in each era to avoid decline and repetition. Among the contemporary poets, ghazal has been popular, and 
poets such as Hossein Monzavi, Mohammad Ali Bahmani, Qaisar Aminpour, and others have created a new style and poetic initiative. It seems that Hossein Monzavi (1946-2004 AH) has used all linguistic tools to promote his sonnet so that his poetry shines on the darkness of contemporary Iranian literature. The present study aimed to review and critique his lyric poems using a model from Jeffrey Leach's theory and determine its linguistic and literary dimensions in the best way possible. In other words, the present study sought to find an answer to the following question: What kind of aberration did Monzavi use to highlight his sonnet?

\section{Objectives and significance of the study}

Further research should be conducted to show the artistic aspect of the isolated lyric poems because previous studies have only expressed the normative deviations of Monzavi's lyric poems and have never analyzed his lyric poems using a specific and independent theory and method. In the present study, the prominence and artistic identification of isolated sonnets is discussed based on Leach's model. Therefore, the present study has two purposes: an answer to the research question and two structural critiques of isolated lyric poems to discover his most frequent artistic trick.

\section{Background of the Study}

Many studies have been conduucted in recent years regarding the innovation and norm-breaking of Hossein Monzavi 's lyric poetry; however, none of the studies has been organized based on a coherent theory and method. The most prominent studies in the field of abnormality of Monzavi's Ghazal are (Moineddin \& Somayeh, 2012), who, in their article entitled "Abnormality in the poetry of Hossein Monzavi " explored different types of abnormality.

In his article entitled "Isolated innovations in lyric poetry", (Farhadi, 2013) dealt with some isolated innovations in the field of grammar, syntax, rhetoric and poetry music and concluded that isolation by removing some of the prevailing constraints on the appearance of the traditional sonnet has made a tangible change in the appearance of the new sonnet. (Khosravi, 2018) in their article entitled "Personal style of Hossein Monzavi 's lyric poems" studied the characteristics of Monzavi's poetry style at three linguistic, literary and intellectual levels.

\section{Materials and Methods}

The present research was conducted using a descriptive-analytical method in accordance with library studies. To explain and analyze the subject, a brief account of structuralism and the concept of construction in Persian literature are presented, and the eight linguistic metaphysics of Jeffrey Leach in Hossein Monzavi 's lyric are then examined and analyzed.

\section{Results}

\section{Theoretical foundations of the discussion}

Undoubtedly, the main early texts of structuralism are the theory of "poetics" or Aristotle's poetry and Horace's treatise on poetry. When Aristotle says, "So, as a matter of necessity, there are six components to tragedy, from which tragedy is composed and whose nature is derived from six things" (Aristotle, 2008). In other words, it does nothing but extracts tragedy and finds the structures consisting it. Interestingly, the term poetics itself is derived from the Greek word poetikos meaning "knowledge of literary structure" and from the root poesis meaning "to make" (Ahmadi, 2013).

Structural critique in its modern sense actually was flourished in the literature in the 1960s in order to apply the methods and perceptions of Ferdinand de Saussure, a Swiss linguist. The 
task of structural critique is to extract the components of the structure of the work (literary elements or literature), establish a link between the components (structural coherence), and exhibit the meaning present in the whole structure of the work (semantic implications of the literary work).

Structuralism less considers the subject of the text and mostly focus on how it affects it. It deliberately reduces the importance of its content to better and more clearly understand the mechanisms of the text. For example, it does not value the moral of the story or the message of a folk tale. The structuralist school, then, distinguishes between the construction of literary and nonliterary language (Monzavi, 2008).

The school of structuralism first began with the study of the structure of language. The scholars of this school believed that language is a social structure and that every culture to reach semantic structures, expand and transform narrations or texts; hence, individuals can organize their experiences and give meaning to data. In other words, structuralism seeks a way to describe and report the internal connection through which meaning is constructed in a culture.

Background of the concept 'structure' in Persian

Structure is the sum of form and content. If a work of art or literature reaches the peak of harmony of form and content, it has reached the ideal structure. Shafiei Kadkani in his book "Music of Poetry" gives a comprehensive definition of structure as follows: "The structure consists of a set of interactions among the components of a whole with each other so that each unit plays the most critical role against the other components" (Shafiei Kadkani, 2013).

In our traditional critique, structure is important and referred to as "tawwif" (poetic art). For example, Shams Qais believes that "It should be free from unlikely metaphors, vain punishments, false similes, and denials, and strangers and desertions should not be used in it" (Mojtaba, 2001).

If we consider the literary tradition of Iranians and even Muslims in general, "we see the general plan of the writers' view as a completely formalist plan. Abdul Qahir Jorjani is a unique formalist. Not only Jorjani but also Hafez is a formalist. When a poet focuses a poem on its surprising point and thus believes that poetry is something that cannot be translated, because in translation, its surprising point disappears and this is another expression of the issue of familiarity, i.e. de-escalation. It is true that. in Hafez and Jorjani's expression, there is no mention of the concept of unfamiliarity; however, these two figures have accepted in practice that the aesthetic criterion in art, and according to their poetry, is a surprising point, and the artist and poet with our own creativity "It makes me wonder" (Shafiei Kadkani, 2013).

It can be seen that the common denominator of traditional critics of Persian literature such as Abd al-Qahir Jorjani and Shams Qais with Russian formalists and structuralists is the attention to the surprising elements of literary texts with titles such as Tafwif, Sha'i Art. Poetics, the structure of literary speech, de-familiarization, norm-breaking, highlighting, etc. are discussed. A set of speech components distinguish speech from ordinary and everyday language. In other words, these elements save the words from death and revive the words (Fazilat, 2011) As Biddle considers poetry as a revival of meanings, which is another perspective of this concept. Biddle! The soul of the worker is the resurrection of meanings because the words of the resurrection are my words (Bidel Dehlavi, 2010).

Surprising and literary augmentation causes delays in receiving artistic words. Formalists call this delay "the time of artistic understanding" or "artistic pleasure." This delay should not be boring and confuse the audience as they do not enjoy reading the text. Shams Qais expresses boredom and confusion with the interpretation of strangers and desertions and has the same view of formalists.

\section{Literary function}

Is such that the audience's attention is drawn to the elements and techniques of literature and arouses his surprise; Because at first glance, he observes a strange thing, contrary to logic, intellect, custom and habit, which is ordinary and sometimes meaningless, and as a result, the audience think more about this issue. "This reflection, which is likely to lead to the discovery of the speech meaning, would give the audience a sense of aesthetics and pleasure" (Chenari, 1998). 
According to a Russian linguist, Roman Jakobson's theory of communication, literary function becomes possible when the emphasis is on the "message" itself. According to Roman Jacobsen's theory of communication (information theory), there are six factors in each linguistic communication. The message is sent from the sender (speaker) to the receiver (reader, listener), and there are three other factors involved in any successful relationship: contact, code, and context. The emphasis on each of the six factors points to a specific function of the message. "Looking at the message from all five factors - except the message itself - we find a different action with a specific function in front of us," he notes. However, only where we pay attention to the message itself and consider its form independently and expressively; "we will become familiar with poetic function or the art of poetry" (Ahmadi, 2013).

In the literary function, the reference of the message is the message itself, so "the message is no longer a means of communication but its subject." (Giro, 2001) This linguistic function has been called by each literary critic. For example, Jacobsen calls it "literary function" and Lamartine calls it "aesthetic function" (Safavid, 2011).

\section{Discussion}

\section{The structure of isolated}

Looking at traditional Persian poetry and creating a gradual change in his vision and attitude and turning to new spaces, Hossein Monzavi could give a new spirit to contemporary lyric poetry, both linguistically and lexically, as well as in terms of content. Contemporary traditionalist poetry considers the phonetic, lexical, and syntactic level of language, and the form of sonnets. Monzavi, who recounted some of his theories in the introduction to his lyric book, "From Sugars and Sugar," writes,

"Nima opened another window on Persian poetry, and although this window opened at a time when Persian poetry was really suffocating, it never meant that all other windows had to be closed ... Do not think that I am capable I testify to all the traditional forms in the worthy help of poetry, the ode of the account is pure, concise and composed, and ... their account was pure from a long time ago. Ghazal and Masnavi remain, which in my opinion can still be used in poetry, successful, and between these two, Ghazal shows itself to be more worthy. "Ghazal's history, its support, its efficiency, and many other things set it apart from other forms of traditional poetry" (Mohammad, 2106).

Ghazal continues its life by contemporary lyricists with external and internal changes. Hossein Monzavi 's contribution includes initiatives and innovations made in the field of phonetics, rhetoric, syntax, etc. The language of his sonnet is highly powerful in the field of selecting old and new words and its syntactic and grammatical level. The linguistic potentials of his sonnet, which are frequently mentioned with themes such as the praise of love, are among his stylistic and special features.

In the introduction of the collection "From Shukran and Shukr", Monzavi mentions: "Today's sonnet must reconcile with words that are considered rejected and non-poetic by the masters; That is, the same thing that Nimayi poetry has done. I find that these words sometimes cause a kind of violence and unevenness in the language. What is wrong with our romantic language being harsh, uneven, and not even polished? "Is not our life and our loves like this?" (Mohammad, 2106). This view made the isolated sonnets be full of compositions highlighting the speech.

\section{Lexical function}

In the lexical method, the poet creates and uses new words in terms of analogy and escaping from the rules of constructing the word of the normal language. He highlights his language by creating new words. "This kind of aberration takes place in two ways: the construction of strange words and the sounds of meaningless words, and it has its first effect on meaning." (Saadi Shirazi, 2010). 
The invention of a new word is one of the most common methods used by the poet in his work to expand and generalize the possibilities of language word formation (Safavid, 2011).

1. In general, isolated compositions in sonnets come in three different forms: 1- Composite words: The most significant part of isolated composition is dedicated to the creation of compounds, adjectives, adverbs and nouns, such as ghamava, kamandazandaz, dargozini, azarakhshaneh, lilyaneh, khasmakhoon, fig, talbakheh, etc. For example, in the following verse, the poet created a new adjective "thankful" by adding the suffix "mand" to the word "thank you":

Thank you for all the hope that it ended with a charisma, the season of my anxiety (Monzavi, 2008). "lily":

In the following verse, Monzavi added the suffix "ane" to "lily" to form the "lily" meaning

If you break the lily, my cup What a pity that the charming way of making beautiful choices (Monzavi, 2008).

In the following verse, the poet used the compound word "glagol" in the meaning of "pregnant" by adding the middle "a" between the two "flowers":

Let this flower garden bloom in color What did I do, flower! What can I do without you? (Monzavi, 2008).

By studying the lyric poems of Hossein Monzavi, it became clear that most of the compound words are used in the form of new adjectives.

2. Descriptive compositions: Another group of compositions and isolated innovations are descriptive compositions, the novelty of which is caused by the connection and attribution between the attribute and the adjective. They are documents created with an in-depth view and in the style of Nimai's modern poets. For example, the previous adjective "narcissus" for "eye" in the following verse: Look like a breeze in the air of a daffodil Seasons I have disturbed the flower collection (Monzavi, 2008).

In Sohrab Sepehri's poetry, such previous attributes are also widely used. For example, the descriptive combination of "one armpit of freedom" in poetry: Life at that time was a line of light and dolls One arm was freedom ... (Sepehri, 2008)

In the isolated sonnet of posterior (expressive) attributes, he sometimes finds a strange and unprecedented relationship with his subject. Like "grief call" in the verse:

We came and stormed your garden Before the mourners arrive (Mohammad, 2106).

In some cases, this connection and strange and unfamiliar documents are established in the form of noun sentences between the predicate and the predicate (attribute and adjective). As: Ms! Hello and thank you that you are green Low wind and lost from the mirror of your boredom (Same, 2015).

3. Additional compositions: The third category is additional compositions in which isolation, with its deep-thinking and poetic art, establishes a novel and unprecedented connection between additions. Such as "Heart of Doubt", "Hand of Truth" and "Wrestling of Illusion" in the following verse:

Love came from the heart of doubt to manifest Because the hand of delusion is the grip of illusion (Same, 2015).

In this category of compositions, the poet with strong imagination and poetic perception of the phenomena of existence, creates new and original images, in whose creation different techniques of expression, especially simile, metaphor and recognition are often used.

\section{Syntactic function (Grammatical)}

In syntactic aberration, the poet goes beyond the syntactic rules of normative language by shifting or changing the constituent elements of the sentence. Monzavi also exhibited this abnormality in his poetry in various ways. His innovations at the level of syntax and sentence structure mostly include the use of sentence components and norm-breaking, which have wide applications and light position in modern poetry. These anomalies are as follows:

1. Conjugating letters: Isolation sometimes changes the location of the letter in the sentence structure. For example, "ta" should be warned before the verb 'to forbid'; however, in the following verse it is separated after the verb: 
Tell a friend or an enemy to rest in my shadow Do not say until I restrain my self-sacrifice (Same, 2015).

2. Using the conjunction letter for brevity: For example, in the following verse, he has used "and" in the second sentence to shorten the sentence.

The pain we wasted, that precious essence

I do not cut and we do not cut, we do not cut and we do not cut (Same, 2015).

3.Uisng long Manada: In many of his sonnets, Monzavi expresses his intentions and desires by addressing Manada and addressing his beloved. In these cases, he often uses long and creative descriptive phrases, bringing a new and original structure to sentences. Like the following verse, the second stanza of which is Manada:

The door closed on everyone because you came $\mathrm{O}$ special the meaning of each general time (Same, 2015).

4. Presenting adjective to the subject: According to the grammatical rules, the expressive adjective comes after the subject; However, Monzavi has innovated in his sonnets and has introduced the adjective before him by adding an extra fraction. "Infinite Desert" in the following verse is an example of this abnormality:

I am the infinite core that is in me

Unplanted except the hand of the seed, the grain (Same, 2015).

5. Having addition between the adjective and the adjective: Isolation sometimes brings the adjective between adjective and adjective to highlight it in this way. It is the same as the composition of the "mirror of nomadic homelessness" in the following verse:

To the night when the mirror of homelessness is scarce To the night when my lonely half is black (Same, 2015).

"Homelessness" is added to "mirror" and adjective "mukdar" that comes after it belongs to "mirror". This method is unprecedented in classical Iranian literature. For example, the composition of "sons of the incomplete minister of reason" in the following verse from "Golestan" by Saadi: 2010).

Sons of the Minister of Imperfect Mind They went to the village begging (Saadi Shirazi,

6. Adding the suffix "wet" to the superlative adjective: The superlative adjective is made by adding the "most" to the simple adjective. In this regard, Monzavi invented and added "wet" as an adjective-making suffix added to the end of the superlative adjective and thus has highlighted the adjective. An example is "the most beautiful" in the following verse:

$\mathrm{O}$ the best allegory of the verbs of difference Do not say you are the most beautiful (Manzooi, 2019).

7. Adding the suffix "the most" to the end of the noun and adverb: Isolated, contrary to the syntactic rule, by adding the suffix "the most" to the end of nouns and adverbs, he started to coin and highlight them. Like the word "someone" in the following verse, which is the name and the suffix "most" is added to it: You are the cutest person and you have to take steps Comrade and Madara with comrades! (Manzooi, 2019).

In the following poem, the word "always" which is an adverb with the suffix "most" is used as a superlative adjective: Your image was the most ever Lady of the Foggy Poems (Manzooi, 2019).

8. Having an unconventional use of syntactic maps: This deviation from this norm can be observed in abundance in isolated lyric poems. For example, the adverb "always" is used in the novice way instead of "name" and accepts syntactic patterns:

Why does the air smell so good today? You do not want to be separated from me forever (Manzooi, 2019).

I always have your scent on your scalp You are not with me and you do not need to smell your shirt (Manzooi, 2019).

Dalan Golafshan Nasim Saba! Salam

O scent of a friend in you forever (Manzooi, 2019).

I always remember that fragrant wet hair in my mind

It floats on the clear chest like moss on the water (Manzooi, 2019). 
Phonological function phonetic

Aberration is a change in the phonetic forms of words in a way that is not common in the norm of language. (Safavid, 2011) In isolated sonnets, the only method of phonetic function is a method of reducing the letters of words. For example, the poet used the words "anesthesia" and "conscious" instead of "anesthesia" and "conscious" in the following verse: Heavy anesthesia, dusty sleep I'm awake and awake this time (Manzooi, 2019). "face":

In the following verse, the poet has given the word "face" with a discount in the form of

What is your sorrow as if you were a sad wretch He cried all his sorrow in this (Roozbeh, 2000). In another example, the first isolator uses the word "wind" and then uses it with a reduction in the form of "wind" in the combination of "windmill":

Until the breeze, the head of Shalalat wig is the buttocks Let go of the wind that blows away (Manzooi, 2019).

More examples are as follows: Miracle (p. 16) instead of miracle, May (p. 96) instead of the moon, Companion (p. 131) instead of companion, Master (p. 174) instead of standing, Khamoush and Faramoussh (p. 478) instead of silence and forgetfulness, etc.

\section{Logical graph function}

In writing anomaly, the poet uses a method in writing that does not create an interpretation in the pronunciation of the word; however, it adds a secondary meaning to the main meaning of the word. Since classical poetry has a certain length and width, the poet cannot use this method of highlighting in composing sonnets. However, there is no example of this literary function in the isolated sonnet.

\section{Dialectical function}

In the method of dialectical abnormality, the poet inserts a word or a term from a language or dialect other than the normal language into the poem, which causes de-familiarization at the verbal level. This method occurs in isolated sonnets only by bringing unfamiliar Arabic words. For example, the word "juice" means abstract and extract:

The Hafiz office? Shirazi wine? What are you? Cain is a warm and attractive species (Manzooi, 2019).

More examples: "Transformation" (d. 41) in the sense of changing from one state to another, "The code of permanence" (d. 58) in the sense of the sign of immortality, "Integrated" (d. 189) in the strong and stable sense, In the sense of abstaining and avoiding, "Mushah" (d. 383) in the meaning of approved and adorned, "Tanjim" (d. 383) in the sense of astronomy and astrology, "Anointing" (d. 444) in the sense of lubrication and oil Finance and ....

\section{Stylistic function}

"The main layer of poetry is its standard writing style. Whenever the poet escapes from this and uses words and syntactic structure of speech, there is a slight deviation from the norm" (Safavid, 2011). In his sonnets, Monzavi used both words and combinations of colloquial language and its syntactic structure. He innovated in the field of vocabulary by inserting slang verbs in the sonnet. For example, the verb "slapping" means "scattering the drops of water or other liquid and rippling" (Dehkhoda, 1998), in the following verse:

The sun shone from the ground on the front of the sun When he gave darkness, he ordered the shooting (Manzooi, 2019).

Sometimes colloquial words are not verbs. Examples are "shula" (rough felt) in the upper verse or "wanderer" in the following verse:

Where in this nostalgia do you fly? Modern questions! You are blocked! (Dehkhoda, 1998).

"One of the features of the new sonnet was the movement towards the health of the language and the adaptation of the context of the modern use of words, which found a serious and 
fundamental form in the sonnet after the revolution and became relatively organized" (Roozbeh, 2000). One of the salient features of the isolated lyric that distinguishes it from the lyric of traditional lyricists is the use of modern words. He used non-poetic words in poetry and highlighted them in this way. An example is the combination of "wall clock" in the following verse:

Shame on you until the hour of that incident Our eyes were fixed on the wall clock (Manzooi, 2019).

He sometimes used scientific and non-poetic words in his poetry and in this way tries to get acquainted. Examples are the medical terms "cancerous glands", "benign" and "malignant" in the following verse:

My hatreds - our cancerous glands - uninterrupted Between anger and my eyes swirled benign or malignant (Dehkhoda, 1998).

At the syntactic level, the poet has used a lot of colloquial language. For example, we can mention the sonnets $21,171,260$ and 347, which are included in the colloquial language. Here is an example:

Wake up your eyes when dawn, wake up in your eyes Hit Saddam to be spring from the sounds of my heart garden (Dehkhoda, 1998).

\section{Semantic function}

Leach believes that the highest unfamiliarity occurs at the level of meaning since the field of meaning, as the most inflexible level of language, is used by poets more than the other levels in highlighting. "The accompaniment of words in semantic aberration is not based on semantic rules governing the norm of language, but is subject to its own rules" (Roozbeh, 2000). Literary language of companionship and substitution, including metaphor, permission, recognition, allusion, paradox and so on, that are not common in the normal language. Here is an example of their use in isolated lyric poems.

A. Ambiguity: Ambiguity is one of the characteristics of the new sonnet which elevates it from death and lethargy and gives new vital words with the resurrection. Monzavi used this novel element a lot and could increase the artistic understanding of his poetry with poetic taste and elegance, encouraging the audience to think and find the secrets of beauty. For example, in the only sonnet that brings his poetic pseudonym (isolated), he added to the beauty of the word with poetic ambiguity: You wounded me deeper than isolation It is not in vain that your "isolation" has failed (Manzooi, 2019).

In this verse, "isolated" in the second meaning has also been considered by the poet.

B. Paradox (Paradoxical): Paradox is one of the techniques to highlight words and a tool for expressing the meaning behind ordinary words and the indirect expression of purpose; therefore, it confuses the audience. Although this novel technique has long been used by great speakers, especially Iraqi style lyricists; however, its application in the works and poems of the contemporary modernists and poets is becoming more widespread. In its widespread use of paradoxes and paradoxes, Monzavi has been influenced by modern not ancient poetry. An example is "in your frequent non-recurring": 1998).

Only your mouth does not pierce your heart A sugar that is infrequent in itself (Dehkhoda,

Or the coincidence of "silence" with "evil world" and the combination of "silence" in the following verse:

Look at my silence now that the world of evil and passion Sleeping in the chest of my screaming silence (Dehkhoda, 1998).

C. Hint: The rebellious mind does not tolerate the isolation of crawling in the isolation of repetitive myths and stereotypes. He does not consider many ancient allusions to be convincing and responsive to the psychological needs of modern man. Accordingly, it collapses them and builds a new building from their bricks in the ground and space of today (Alavi Moghaddam, 2002). Here is an example:

The madness of the deserts is the legend of abandonment My night now, I am crazy about the streets (Manzooi, 2019). 
D. Observations: This array plays a significant role in the decoration and beauty of isolated words. Sometimes, isolation brings several such observations in one verse:

Twenty notebooks and your pencil sharpener To what extent does it play a role, Farhadi cream of the Aban (Roozbeh, 2000).

"Biston", "Tisheh", "Shirin" and "Farhad" are among the elements of Shirin and Farhad's story, and "Daftar", "Qalam" and "Khameh" are of the same category of stationary.

E. Simile: Simile is the most frequently used and diverse expression array in isolated sonnets. He places a great emphasis on inventing and presenting new similes. His innovations in simile are presented in three forms:

(1) Renewing old and old similes: metaphors that have an old and stereotypical basis, he presents them in new clothes and cover with different methods and tricks. For example, the poet (lover) in his metaphor of the hot tulip, which is a completely clichéd metaphor, uses the industry of recognizing and documenting new and innovative traits to innovate as follows:

Chou tulips washed in blood, mourning clothes I am now and the hot line of spectators is by my side (Roozbeh, 2000).

2. Creating a new connection (and pseudo-face) between the parties of the simile: The novelty of some isolated similes is due to the discovery of a new relationship between the similar and the similar and the creation of a new pseudo-face. Like:

A bouquet in front of my bouquet A flower ring around your neck is my arm ring (Roozbeh, 2000). In the first stanza, the poet likens his kisses to a bouquet, and the face is like a bouquet and is numerous.

3. Creating similes with a new structure: Most of the isolated similes have a new and unprecedented structure, indicating that the poet uses special linguistic and expressive techniques and methods in creating them. For example, in the following verse, in the first reading, the reader is confronted with two singular-to-singular metaphors in which the pronoun "I" is implicit in both "cloud" and "breeze", similar to "beh" and "crying" and "flower". They form a quasi-face:

Sometimes I get a cloud around your skirt When I get a breeze from the branch (Roozbeh, 2000).

But with a little reflection we find that in addition to recognizing the clichés in "Crying the Cloud" and "Blooming the Breeze", the poet also used a McNean metaphor in each of the two similes: (You) to "mountain" which is mentioned as similar to (mountain) its skirt (slope) and in the second stanza your (beloved) likeness to "Golestan" which is mentioned as similar to its "flower and branch". Or the "branches" can be added to the metaphor, in which case the reader realizes that instead of singular to singular metaphors in each stanza there is a composite metaphor with a new structure. The first shutter: I weep for your skirt like a cloud that falls at the foot of the mountain, the second shutter: I pick flowers (kisses) from the tree in Golestan Khorram or from the green tree of your existence, just like breeze from Gulben flowers.

F. Metaphor: Metaphor in enlightened sonnet has an enlightening function and is used as a method and tool for effective expression of the poet's intentions and concepts and increases the influence of words in the reader. He often uses explicit metaphors, and in some cases, simple and easy-to-understand metaphors. He has metaphors that are difficult and far-fetched, and metaphors that make it difficult to be detected. (e.g., Anadiyeh and Makineh refuse to be deceived); hence, we sometimes come across with some old metaphors and clichés in his sonnets. As:

I'm so tired of my life and myself, how far as much as one breath in the shade of serot (Roozbeh, 2000).

To clarify his metaphors, he also uses the nickname Leh and the nickname $M e$ in the verse. For example, in the following verse, first the nickname ل (love) is mentioned in the first stanza, and then in the second stanza, it is mentioned once more metaphorically and with the pseudonym "Azarakhsh": Not from me, to the ashes, you also burn from love If you have a fire from Azarakhsh, you are in fire (Roozbeh, 2000).

G. Recognition: Recognition is often used in isolated sonnets, often in a pristine and simple way, to clearly express the poet's intentions and effectively convey the concepts contained in his verses. An example is as follows:

Which to show on the fish 
Always tell the mirror and the water (Roozbeh, 2000).

The recognition used in "Mirror" and "Water", and "Say and Say" between the two is to effectively express the description of Jamale Yar (the beloved's appearance). This "say and say" in addition to the wavy image of the moon in the water and the instability of the image of the companion in the moving mirror and "saying and saying", the competition of rivals with the lover over watching and possessing the beloved, it evokes appearance and beauty.

H- Irony: Most of the allusions of the sonnet are isolated from the source irony or verb, which is the most common type of irony. In this kind of irony, he is to use slang words and combinations to convey his words to the audience more simply and explicitly. All his allusions are simple and easy in terms of clarity and secrecy. Similarly, "heart to sea" means not to be afraid:

What a beautiful sea your eyes are This is where you have to go to sea (Roozbeh, 2000).

\section{Function in time (Historical Period)}

Sometimes the poet escapes from the temporal form of normal language and uses forms that were previously common in the language and today are considered dead and obsolete syntactic words or constructions. Leach calls this kind of literary function "in time." The "in time" function is divided into two forms of lexical archeology (lexical archeology) and archaic construction (syntactic archeology). In his sonnets, Monzavi used both types of aberrations "in time".

A- Vocabulary archeology: Vocabulary archeology has been used in two forms of reviving dead words and ancient pronunciation of words in isolated poetry.

1. Revival of non-existing words: The poet uses words that are no longer used in today's language and are unfamiliar to linguists. For example, "does not know" means "cannot" in the following verse: You are the eternal image that even death is magical He does not know the role of my conscience (Manzooi, 2019).

2. Ancient pronunciation of words: The poet sometimes uses ancient pronunciation of words that are used today with changes in pronunciation. An example is "Espand" in the following verse, which is the old form of "Esfand": I emptied myself and did not reach the state Finally, how much is this pecan seed? (Roozbeh, 2000).

B. Syntactic archeology: The poet's is to construct the syntax of the past, which is not used today in the normal language. For example, the use of the adverb "no" separate from the verb "to negate' is closer to the Iraqi style. Like: Nine spring hands play my body Not a chicken to the plow (Same, 2015).

\section{Conclusion}

Influenced by Nima's modernist thought, Monzavi has created pristine poems with new themes in the traditional form of lyric poetry and has given new life to contemporary lyric poetry. He does not seek to create artistic ambiguity and complexity and is to bring his language closer to everyday language and norm with simple innovations. Although his language is new, it does not confuse the audience. Artistic innovations and simplicity in the expression of lyric poetry have made him "easy to refrain" and distinguish him from contemporary lyricists. The simplicity of his language can be observed in the highlights of Leach's pattern. At the lexical level, he uses "words" to create new words that, when added to the word, the audience then can understand the new word. At the syntactic level, he has tried to make it understandable and close to the slang language by moving the components of the word. At the phonetic level, he is to use words in poetry that are mostly used in everyday language only through mitigation. At the dialect level, he includes only a few relatively difficult Arabic words in the sonnet. At a light level, he uses colloquial words, especially verbs common among the public, to make his language simpler and more sincere. At the semantic level, it is to innovate the used and repetitive industries with a new look to intervene and occupy the relations among its constituent components. This innovation is in the intellectual stream of the poet's simplicity. On the surface at some point, he uses no difficult vocabulary and syntactic construction, and this linguistic metaphor does not interfere with 
understanding the poetry. In general, isolation from linguistic aberrations has paid the highest attention to semantic aberrations. In this way, he was to create new and pristine images and used more expressions of lexical, syntactic and stylistic deviations in his poetry. Of the three functions of phonetics, dialect was found once in his sonnet. The written function also had no place in the studied poems, according to the format of the sonnet.

\section{References}

Safavid K. (2011), From Linguistics to Literature (2 volumes), 3rd edition, Tehran, Surah Mehr Publications, 15(4): 32-53.

Shafiei Kadkani M. (2013), Poetry Music, Tehran: Agha Publications, 13(6): 148-160.

Sojudi F. (1999), "The illusion of a critical presence on Leach's norm-breaking and the principle of Shafiei Kadkani's media", Art, 42(18): 22-18.

Khalili Jahanatigh M. (2001), Sib Bagh Jan, Tehran: Sokhan Publications, 7(3): 24-27.

Moineddin F. \& Somayeh S. (2012), "Abnormality in the Poetry of Hossein Monzavi ", Prose Study of Persian Literature (Literature and Language), 31(15): 372-350.

Farhadi N. (2013), "Isolated innovations in lyric poetry", Exploration of Persian Language and Literature, 26(14): 360-321.

Khosravi H. (2018), "Personal style of Hossein Monzavi 's lyric poems", Stylistics of Persian poetry and prose (Bahar Adab), 40(11): 153-174.

Aristotle F. (2008), Aristotle's Poetry, translated by Abdolhossein Zarrinkoob, 6th edition, Tehran: Amirkabir Publications, 11(2): 37-74.

Ahmadi B. (2013), Text Structure and Interpretation, 15th Edition, Tehran: Markaz Publishing, 25(4): 704-719.

Monzavi H. (2008), From Shokran and Shokr: Ghazal Collection, 4th Edition, Tehran: Afarinesh Publications, 9(1): 22-38.

Mojtaba M. (2001), New Innovation: The Art of Making and Arranging Sokhan, Tehran: Sokhan Publications, 18(5): 117-129.

Fazilat M. (2011), Principles and Classification of Literary Criticism, Tehran: Zovar Publications, 14(2): 197-221.

Bidel Dehlavi A. (2010), Divan (2 volumes), edited by Akbar Behdarvand, 2nd edition, Tehran: Negah Publications, 8(5): 11-27.

Chenari A. (1998), Contradictions in Persian Poetry, Tehran: Farzanrooz Publishing, 15(3): 6980.

Giro P. (2001), Semiotics, translated by Mohammad Nabavi, Tehran: Agah Publications, 14(1): 22-34.

Mohammad F. (2106), Acollection of poems, 5th edition, Tehran: Negah Publications, 6(2): 2234.

Saadi Shirazi M. (2010), Generalities, edited by Mohammad Ali Foroughi, 2nd edition, Tehran: Shaghayegh Publications, 17(3): 119-134.

Sepehri S. (2008), eight books, Tehran: Tahoori, 29(2): 276-289.

Same N. (2015), Structure and Hermeneutics, 6th edition, Tehran: Gam No Publications, 16(1): $58-70$.

Manzooi D. (2019), The Resurrection of Words, 5th edition, Tehran: Sokhan Publications, 7(8): 335-349.

Dehkhoda A. (1998), Dictionary, 2nd Edition, Tehran: University of Tehran Press, 16(1): 58-70.

Roozbeh M. (2000), The evolution of Persian lyric poetry from the Constitution to the Revolution, Tehran: Rozaneh Publications, 16(1): 141-152.

Alavi Moghaddam M. (2002), Theories of Contemporary Literary Criticism, 2nd Edition, Tehran: Samat Publications, 18(3): 170-185. 